Check for updates

Cite this: RSC Adv., 2018, 8, 30076

Received 6th August 2018

Accepted 11th August 2018

DOI: $10.1039 / c 8 r a 06619 a$

rsc.li/rsc-advances

\section{Highly reactive 2-deoxy-2-iodo-D-allo and D-gulo pyranosyl sulfoxide donors ensure $\beta$-stereoselective glycosylations with steroidal aglycones $\uparrow$}

\author{
Jordi Mestre, David Collado, David Benito-Alifonso, Miguel A. Rodríguez, \\ M. Isabel Matheu, (D) Yolanda Díaz, (D) Sergio Castillón (iD) and Omar Boutureira (D)*
}

\section{Introduction}

2-Deoxy- and 2,6-dideoxy- $\beta$-glycosides are common architectures present in many biologically active ingredients such as antibiotics, appetite suppressants, and nucleosides. ${ }^{1}$ These deoxyglycosides, and especially cardiac glycosides (e.g., cardenolides N1 from Nerium oleander or those from chrysomelid beetles, ${ }^{3}$ and helveticoside ${ }^{4}$ ), are usually composed of uncommon glycosyl moieties including $\mathrm{D}$-ribo and $\mathrm{D}$-xylo-configured pyranoses (Fig. 1). While these glycoconjugates, with the general structure [sugar $]_{n}$-aglycone, are nicely produced in nature, most of the chemical glycosylation approaches ${ }^{5}$ for their preparation are mainly focused on the sugar-sugar motif but are still inefficient for the $\beta$-stereoselective synthesis of the sugar-steroid portion. In addition, the $\beta$-stereoselectivity is typically better for the construction of the sugar-sugar motif (up to only $\beta$ ) compared to that of the sugar-steroid fragment (up to $9: 1 \beta / \alpha$ ) and thus, the latter glycosylation step represents the overall "stereoselective determining step" in 2-deoxy and 2,6-dideoxyglycoconjugates featuring such particular configurations. ${ }^{5,6}$ Our group has developed an indirect ${ }^{7}$ synthetic approach for the stereoselective synthesis of 2-deoxy- and 2,6-dideoxy-2-iodoglycosides that utilizes 2-deoxy-2-iodo-1-thioglycoside donors, being particularly effective for the production of $\beta$-D-allo and $\beta$-D-gulo pyranosides. ${ }^{2,8-10}$ The resulting configuration is predefined by the starting furanose and thus, D-ribo and D-xylo structures serve as configurational templates for $\mathrm{D}$-allo and $\mathrm{D}$-gulo pyranosides, respectively. Our findings determined the key $\beta$-selective

Departament de Quimica Analitica i Quimica Orgànica, Universitat Rovira i Virgili, C/Marcel·lí Domingo 1, 43007 Tarragona, Spain. E-mail: omar.boutureira@urv.cat $\dagger$ Electronic supplementary information (ESI) available. See DOI: $10.1039 / \mathrm{c} 8 \mathrm{ra06619a}$ glycosylation step is kinetically-controlled and the presence of iodine favours the stereoselective formation of a 1,2-trans glycoside via the least energetic transition state upon preferential nucleophilic attack to the oxonium intermediate ${ }^{3} \mathrm{H}_{4}$. This is consistent with the Felkin-Anh-Eisenstein 1,2-induction model with stabilizing hyperconjugative interactions between $\sigma_{\mathrm{C}-\mathrm{I}}^{*}$ and $\sigma_{\mathrm{C}-\mathrm{OR}}$ (Scheme 1). According to most current models, ${ }^{11}$ the stereoselectivity is determined by the interplay between (a) the ground-state conformational preferences of oxocarbenium intermediates $\left({ }^{4} \mathrm{H}_{3}\right.$ vs. $\left.{ }^{3} \mathrm{H}_{4}\right)$ in which electronegative substituents such as I and OBn prefer a pseudo-axial disposition due to stabilizing electrostatic and/or hyperconjugative interactions (e.g., between $\sigma_{\mathrm{C}-\mathrm{I}}$ and $\pi_{\mathrm{C}-\mathrm{O}}^{*}$ ) and (b) the relative reactivity of each conformer under the $\mathrm{S}_{\mathrm{N}} 1$ paradigm, according to a CurtinHammett kinetics scenario. In this context, while glycosylations of 2-deoxy-2-iodo-1-thioglycosides with sugar acceptors proceed at $c a .-40{ }^{\circ} \mathrm{C}$ and provided reasonably good selectivities (up to $16: 1 \beta / \alpha$ ), we observed a reduction to $8: 1 \beta / \alpha$ with steroidal aglycones (Scheme 1). ${ }^{8}$ We reasoned that prior oxidation of the 1thiophenyl donor to a glycosyl sulfoxide ( $\mathrm{SPh} \rightarrow \mathrm{S}(\mathrm{O}) \mathrm{Ph})$ would enhance its reactivity enabling activation at lower
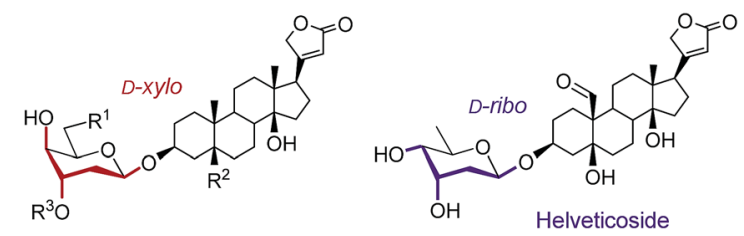

$\mathrm{R}^{1}=\mathrm{R}^{2}=\mathrm{H}, \mathrm{R}^{3}=$ Me Cardenolide $\mathrm{N}-1$ from Nerium oleander $\mathrm{R}^{1}=\mathrm{R}^{2}=\mathrm{OH}, \mathrm{R}^{3}=\mathrm{H}$ Cardenolide from chrysomelid beetles

Fig. 1 Naturally occurring 2 -deoxy and 2,6-dideoxy- $\beta$-glycosides with "rare" $\mathrm{D}-x y l o$ and $\mathrm{D}$-ribo configurations. 

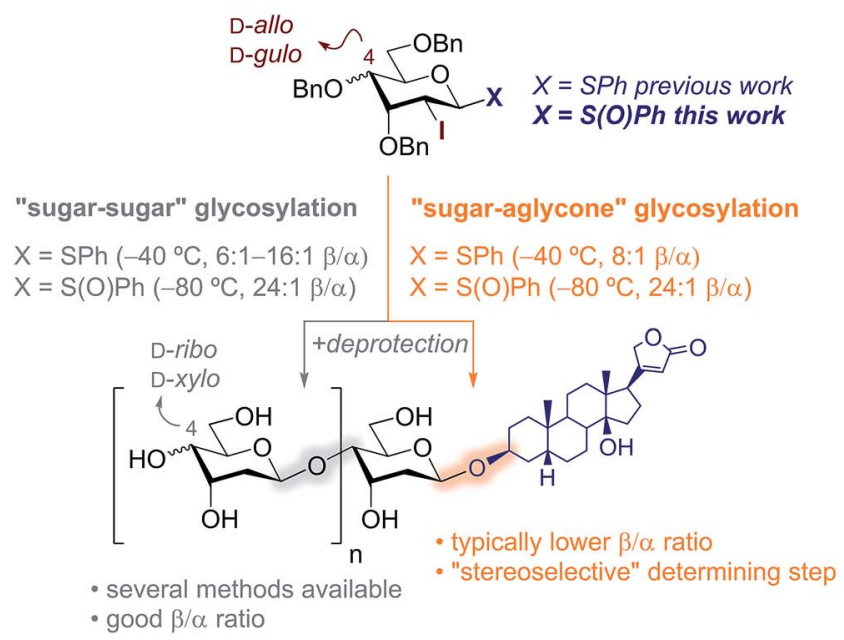

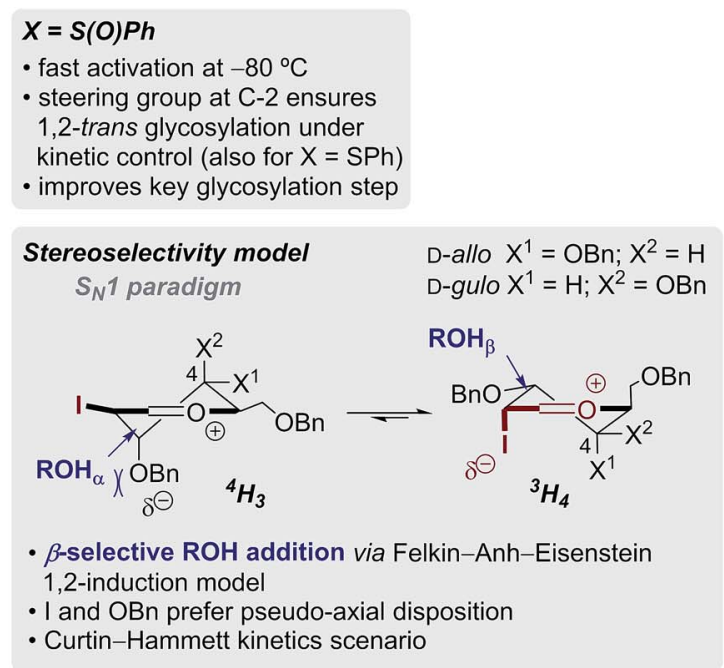

$X=S(O) P h$

kinetic control (also for $X=\mathrm{SPh}$ )

reoselectivity mode

D-allo $\mathrm{X}^{1}=\mathrm{OBn} ; \mathrm{X}^{2}=\mathrm{H}$

-gulo $X^{1}=H ; X^{2}=O B n$

(20) $x^{2}$

1,2-induction model

- Curtin-Hammett kinetics scenario

Scheme 1 Scope and limitations of the stereoselective synthesis of $\beta$-steroidal glycosides of $D$-ribo and D-xylo configurations - using sulfoxides to improve key "sugar-aglycone" glycosylation step.

temperatures. ${ }^{\mathbf{1 2 , 1 3}}$ Hence, iodine control will perform better at lower temperatures restoring the kinetic control in challenging glycosylations as those using steroidal aglycones, favouring the selective formation of $\beta$-glycosides.

\section{Results and discussion}

Preliminary oxidation studies of 1 with $m \mathrm{CPBA}\left(\mathrm{in} \mathrm{CHCl}_{3}\right)^{13}$ and Selectfluor ${ }^{\mathrm{TM}}$ (in $\left.\mathrm{CH}_{3} \mathrm{CN}\right)^{\mathbf{1 4}}$ revealed the high reactivity of the resulting sulfoxide 2 , which evaded isolation due to decomposition. The best protocol used $m$ CPBA as the sole oxidant in $\mathrm{CH}_{2} \mathrm{Cl}_{2}$ from $-80{ }^{\circ} \mathrm{C}$ to $-50{ }^{\circ} \mathrm{C}$, followed by neutralization of the residual benzoic acid with $\mathrm{NaHCO}_{3}$, removal of the precipitate, and conducting the following glycosylation in sequence (Table 1). Thus, dichloromethane perfectly combines chemical inertness towards oxidants, good oxidation rate of sulfides using peroxy acids at the low temperatures necessitated to avoid decomposition, ${ }^{\mathbf{1 5}}$ and good $\beta$-selective properties in the subsequent glycosylation reaction with sulfoxides (up to $3: 1 \beta / \alpha$ ratio with $\mathrm{Bn}$ as protecting groups). ${ }^{13}$ To verify the formation of 2 , oxidation was monitored by ${ }^{1} \mathrm{H}$ NMR in $\mathrm{CD}_{2} \mathrm{Cl}_{2}$ (Scheme 2). The signal peak at $5.10 \mathrm{ppm}$ corresponding to the $\mathrm{H}-1$ proton of the predominant $1 \beta$-anomer was gradually converted to two new doublets at 5.14 and $5.02 \mathrm{ppm}$, tentatively assigned to $2 \beta(S)$ and $2 \beta(R)$, respectively with a $88: 12 \mathrm{dr}$. Although the signal of $2 \beta(S)$ was gradually shifted upfield upon warming from -70 to $-15^{\circ} \mathrm{C}$, the $\Delta \delta$ of $c a$. $0.2 \mathrm{ppm}$ between the two stereoisomers was in accordance with previously reported diastereomeric sulfoxides. ${ }^{16}$

The identity of 2 was further confirmed by high-resolution mass spectrometry analysis (HRMS). Next, glycosylation was explored comparing the selectivities obtained for the activation of 1 and 2 (Table 1). Standard glycosylation using 1-thiophenyl donor 1 resulted in excellent $\beta$-stereoselectivities with primary 4nitro-benzyl alcohol 3a (up to $30: 1 \beta / \alpha$ ) and secondary methyl glucoside alcohol $3 \mathbf{b}(16: 1 \beta / \alpha)$ (entries 1 and 3$){ }^{8}$ In contrast, employing cholesterol $3 \mathbf{c}$ as representative steroidal acceptor substantially decreased the selectivity to $8: 1 \beta / \alpha$ ratio and the thermodynamically more stable $\alpha$-anomer could not be separated from its $\beta$-counterpart. Alternatively, oxidation of $\mathbf{1}$ followed by activation using the $\mathrm{Tf}_{2} \mathrm{O} / \mathrm{DTBMP}$ system at $-80{ }^{\circ} \mathrm{C}$ afforded the corresponding glycosides in very short reaction times and good yields (up to $80 \%$ ). Glycosylation with primary benzylic 3a and

Table 1 Glycosylation scope (SPh vs. S(O)Ph) ${ }^{a}$

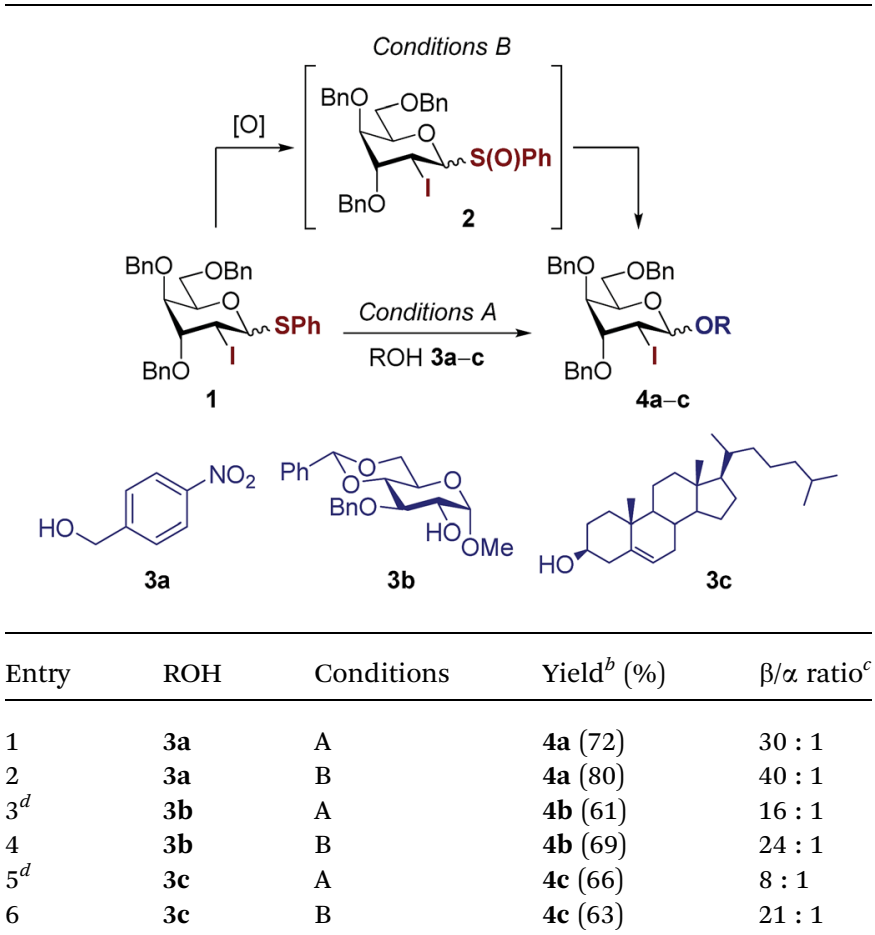

${ }^{a}$ Conditions A: 1 (1 mmol), ROH 3a-c $(2 \mathrm{mmol})$ and 4 Å molecular sieves (MS) in $\mathrm{CH}_{2} \mathrm{Cl}_{2}(4 \mathrm{~mL})$ at $-80{ }^{\circ} \mathrm{C}$. Then, addition of NIS $(3 \mathrm{mmol})$ and TfOH $(0.2 \mathrm{mmol})$ at $-80{ }^{\circ} \mathrm{C}$ to $-40{ }^{\circ} \mathrm{C}$. Conditions B: $1(1 \mathrm{mmol})$, $m$ CPBA $(1.1 \mathrm{mmol})$ and $4 \AA \mathrm{MS}$ in $\mathrm{CH}_{2} \mathrm{Cl}_{2}(30 \mathrm{~mL})$ at $-80^{\circ} \mathrm{C}$. Then, $\mathrm{NaHCO}_{3}(5 \mathrm{mmol})$, filtration and addition of ROH 3a-c $(2 \mathrm{mmol})$, DTBMP ( $3 \mathrm{mmol}), 4 \AA \mathrm{MS}$ and $\mathrm{Tf}_{2} \mathrm{O}(2 \mathrm{mmol})$ at $-80{ }^{\circ} \mathrm{C}$. ${ }^{b}$ Isolated yield. ${ }^{c}$ Calculated by integration of anomeric protons in the ${ }^{1} \mathrm{H}$ NMR spectrum of the crude reaction mixture. ${ }^{d}$ See ref. 8. 


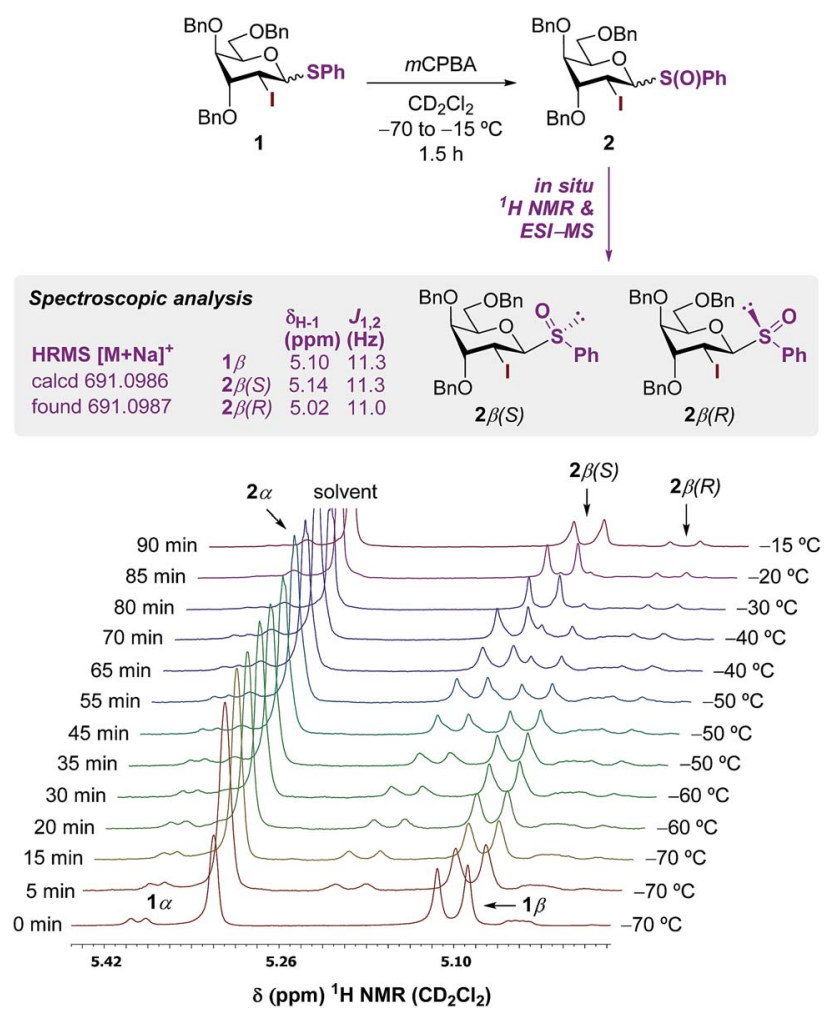

Scheme 2 VT-NMR monitoring of the oxidation of 1.

secondary sugar acceptors $\mathbf{3 b}$ slightly improved the selectivity up to $40: 1 \beta / \alpha$ (entries 2 and 4 ). To our delight, glycosylations using cholesterol $3 \mathbf{c}$ reached comparable levels of stereocontrol (up to $21: 1 \beta / \alpha)$ only when sulfoxide was used as the glycosyl donor (entries 5 and 6). Thus, merging the excellent stereodirecting group properties of $\mathrm{I}^{\mathrm{8}, 9}$ and the lower reaction temperature enabled by the reactive sulfoxide ensured excellent kinetic control with challenging steroidal aglycones.

Finally, the unique combination of oxidation/glycosylation sequence of this strategy was utilized for the synthesis of 2deoxy-2-iodo- $\beta$-pyranosides 7 and $\mathbf{8}$ with high stereoselectivities $(>22: 1 \beta / \alpha)$ and good yields (up to $64 \%$ ) using the steroidal acceptor digitoxigenin 6 and D-gulo- and D-allo-1-thiopyranosides 1 and $5 \mathbf{a}$ as glycosyl donors (Scheme 3). The stereochemistry of the C-4 substituent had little effect on the selectivity although the slight improvement in the $\mathrm{D}$-allo configuration may be explained by the less entropically disfavored $\beta$-transition state resulting from the stabilizing pseudoaxial positioning of $\mathrm{OBn}$ in the ${ }^{3} \mathrm{H}_{4}$ conformer (Scheme 1). ${ }^{11,17}$ Elaboration of 7 and 8 under conventional deiodination and debenzylation conditions ${ }^{2}$ afforded final 2deoxy cardiac glycosides $\mathbf{9}$ and $\mathbf{1 0}$ in excellent yields (up to 95\%).

Likewise, cholesterol $\mathbf{3 c}$ was subjected to the same oxidation/ glycosylation sequence with the more challenging 2,6-dideoxy glycosyl donor $\mathbf{5 b}$ to afford 2,6-dideoxy-2-iodo-D-allo derivative 11 with good stereoselectivity $(20: 1 \beta / \alpha)^{2,9 d}$ and moderate overall yield (52\%). Final products $\mathbf{9}$ and $\mathbf{1 0}$ as well as their precursors $7, \mathbf{8}$ and $\mathbf{1 1}$ adopted a ${ }^{4} \mathrm{C}_{1}$ conformation as determined by NOE experiments and the analysis of diagnostic coupling constants $\left({ }^{3} J_{1,2} \sim 9 \mathrm{~Hz}\right.$ and $\left.{ }^{1} J_{\mathrm{C} 1-\mathrm{H} 1} \sim 163 \mathrm{~Hz}\right)$.

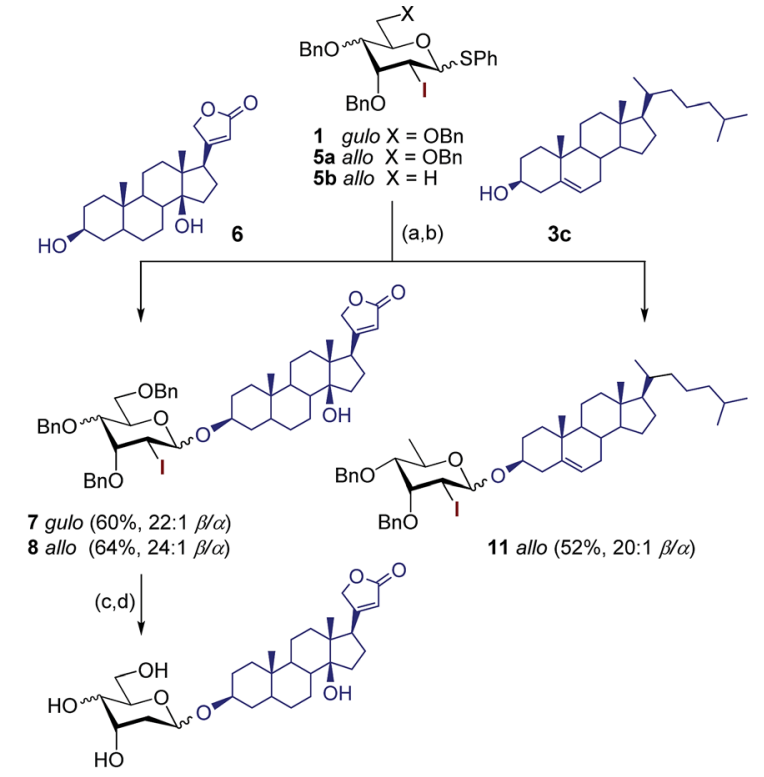

9 xylo $(86 \%, 22: 1 \beta / \alpha)$ 10 ribo $(95 \%, 24: 1 \beta / \alpha)$

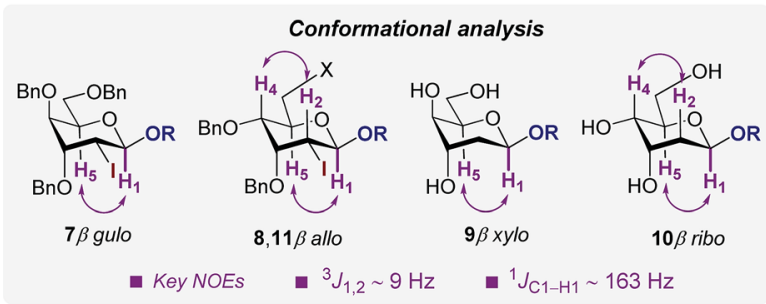

Scheme 3 Synthesis of 2-deoxy- and 2,6-dideoxy-2-iodo- $\beta$-pyranosides 7, 8 and 11 and deprotection steps to digitoxigenyl 2-deoxy- $\beta$-Dxylo and $\mathrm{D}$-ribo cardiac glycosides 9 and 10. Reagents and conditions: (a) $m C P B A, 4 \AA \mathrm{MS}, \mathrm{CH}_{2} \mathrm{Cl}_{2}$ from $-80{ }^{\circ} \mathrm{C}$ to $-40{ }^{\circ} \mathrm{C}$, $30 \mathrm{~min}$; (b) 3,6 , DTBMP, $4 \AA \mathrm{MS}, \mathrm{Tf}_{2} \mathrm{O},-80^{\circ} \mathrm{C}, 30 \mathrm{~min}$; (c) $\mathrm{Bu}_{3} \mathrm{SnH}$, Et ${ }_{3} \mathrm{~B}$, toluene, $\mathrm{rt}, 1 \mathrm{~h}$; (d) $\mathrm{H}_{2}$ (1 atm), $10 \% \mathrm{Pd} / \mathrm{C}, 1: 1 \mathrm{EtOAc} / \mathrm{MeOH}, 0{ }^{\circ} \mathrm{C}, 1-3 \mathrm{~h}$.

\section{Conclusions}

In conclusion, the present work upgrades the previous reported methodology (using 1-thioglycosides) for the stereoselective synthesis of 2-deoxy- $\beta$-glycosides with D-ribo and D-xylo configurations, improving the overall $\beta$-control using challenging steroidal aglycones. The enhanced reactivity of glycosyl sulfoxides and the presence of an equatorial steering iodine permitted the precise formation of complex 2-deoxy- $\beta$-glycosides after removal of the temporary directing element. We expect that the present protocol will find broad application in the chemical synthesis of steroidal glycosides for the medicinal research field.

\section{Conflicts of interest}

There are no conflicts to declare.

\section{Acknowledgements}

We thank the Spanish Government-MINECO and the national agency of investigation-AEI (CTQ2017-89750-R and CTQ2017- 
90088-R), the European Regional Development Fund, and the Universitat Rovira i Virgili (Martí Franquès Research Fellowship Programme to J. M. and D. C.) for financial support. We also thank Arnau R. Rubio for preliminary experiments. O. B. is a Ramón y Cajal Fellow (RYC-2015-17705).

\section{Notes and references}

1 (a) B. Heasley, Chem.-Eur. J., 2012, 18, 3092; (b) J. Zhang, H. Shi, Y. Ma and B. Yu, Chem. Commun., 2012, 48, 8679; (c) R. M. De Lederkremer and C. Marino, Adv. Carbohydr. Chem. Biochem., 2008, 61, 143; (d) H. P. Albrecht, in Naturally Occurring Glycosides, ed. R. Ikan, Wiley, Chichester, 1999; (e) A. C. Weymouth-Wilson, Nat. Prod. Rep., 1997, 14, 99; $(f)$ L. D. Nord, N. K. Dalley, P. A. McKernan and R. K. Robins, J. Med. Chem., 1987, 30, 1044; (g) A. Kirschning, A. F.-W. Bechthold and J. Rohr, Top. Curr. Chem., 1997, 188, 1.

2 J. Mestre, M. I. Matheu, Y. Díaz, S. Castillón and O. Boutureira, J. Org. Chem., 2017, 82, 3327.

3 D. Daloze, F. Broeders, J.-C. Braekman, J. Araujo and J. M. Pasteels, Biochem. Syst. Ecol., 1995, 23, 113.

4 T. Nakamura, Y. Goda, S. Sakai, K. Kondo, H. Akiyama and M. Toyoda, Phytochemistry, 1998, 49, 2097.

5 (a) C. S. Bennett and M. C. Galan, Chem. Rev., 2018, DOI: 10.1021/acs.chemrev.7b00731; (b) J. Zeng, Y. Xu, H. Wang, L. Meng and Q. Wan, Sci. China: Chem., 2017, 60, 1162; (c) S. Medina and M. C. Galan, in Carbohydrate Chemistry, Royal Society of Chemistry, Cambridge, 2016, 41, p. 59; (d) A. Borovika and P. Nagorny, J. Carbohydr. Chem., 2012, 31, 255; (e) D. Hou and T. L. Lowary, Carbohydr. Res., 2009, 344, 1911; $(f)$ C. H. Marzabadi and R. W. Franck, Tetrahedron, 2000, 56, 8385.

6 (a) J. Zeng, G. Sun, R. Wang, S. Zhang, S. Teng, Z. Liao, L. Menga and Q. Wan, Org. Chem. Front., 2017, 4, 2450; (b) K. N. Baryal, S. Adhikari and J. Zhu, J. Org. Chem., 2013, 78, 12469; (c) Y. Ma, Z. Li, H. Shi, J. Zhang and B. Yu, J. Org. Chem., 2011, 76, 9748; (d) H. Tanaka, A. Yoshizawa and T. Takahashi, Angew. Chem., Int. Ed., 2007, 46, 2505; (e) M. Zhou and G. A. O'Doherty, J. Org. Chem., 2007, 72, 2485; (f) K. Toshima, Carbohydr. Res., 2006, 341, 1282; $(g)$ M. Zhou and G. A. O'Doherty, Org. Lett., 2006, 8, 4339; (h) F. E. McDonald and K. S. Reddy, Angew. Chem., Int. Ed., 2001, 40, 3653; ( $i$ ) F. E. McDonald, K. S. Reddy and Y. Díaz, J. Am. Chem. Soc., 2000, 122, 4304; (j) K. Wiesner, T. Y. R. Tsai and H. Jin, Helv. Chim. Acta, 1985, 68, 300.

7 (a) S. K. Battina and S. Kashyap, Tetrahedron Lett., 2016, 57, 811; (b) H. Wang, J. Tao, X. Cai, W. Chen, Y. Zhao, Y. Xu, W. Yao, J. Zeng and Q. Wan, Chem.-Eur. J., 2014, 20, 17319; (c) M. De Castro and C. H. Marzabadi, Tetrahedron, 2010, 66, 3395; (d) T. B. Durham and W. R. Roush, Org. Lett., 2003, 5, 1871; (e) P. Y. Chong and W. R. Roush, Org. Lett., 2002, 4, 4523.

$8 \mathrm{M}$. A. Rodríguez, O. Boutureira, X. Arnés, Y. Díaz, M. I. Matheu and S. Castillón, J. Org. Chem., 2005, 70, 10297. 9 (a) A. Kövér, O. Boutureira, M. I. Matheu, Y. Díaz and S. Castillón, J. Org. Chem., 2014, 79, 3060; (b)
O. Boutureira, M. I. Matheu, Y. Díaz and S. Castillón, RSC Adv., 2014, 4, 19794; (c) I. Cobo, M. I. Matheu, S. Castillón, O. Boutureira and B. G. Davis, Org. Lett., 2012, 14, 1728; (d) M. A. Rodríguez, O. Boutureira, M. I. Matheu, Y. Díaz and S. Castillón, Eur. J. Org. Chem., 2007, 2470; (e) M. A. Rodríguez, O. Boutureira, M. I. Matheu, Y. Díaz, S. Castillón and P. H. Seeberger, J. Org. Chem., 2007, 72, 8998; ( $f$ ) O. Boutureira, M. A. Rodríguez, M. I. Matheu, Y. Díaz and S. Castillón, Org. Lett., 2006, 8, 673.

10 (a) O. Boutureira, M. A. Rodríguez, Y. Díaz, M. I. Matheu and S. Castillón, Carbohydr. Res., 2010, 345, 1041; (b) O. Boutureira, M. A. Rodríguez, D. Benito, M. I. Matheu, Y. Díaz and S. Castillón, Eur. J. Org. Chem., 2007, 3564; (c) O. Boutureira, M. I. Matheu, Y. Díaz and S. Castillón, Carbohydr. Res., 2007, 342, 736.

11 (a) A. Martin, A. Arda, J. Désiré, A. Martin-Mingot, N. Probst, P. Sinaÿ, J. Jiménez-Barbero, S. Thibaudeau and Y. Blériot, Nat. Chem., 2016, 8, 186; (b) M. T. C. Walvoort, J. Dinkelaar, L. J. van den Bos, G. Lodder, H. S. Overkleeft, J. D. C. Codée and G. A. van der Marel, Carbohydr. Res., 2010, 345, 1252; (c) M. Heuckendorff, C. M. Pedersen and M. Bols, Chem.-Eur. J., 2010, 16, 13982; (d) D. Hou, H. A. Taha and T. L. Lowary, J. Am. Chem. Soc., 2009, 131, 12937; (e) M. G. Beaver, S. B. Billings and K. A. Woerpel, J. Am. Chem. Soc., 2008, 130, 2082; (f) D. M. Smith and K. A. Woerpel, Org. Biomol. Chem., 2006, 4, 1195; $(g)$ F. Bravo, A. Viso, E. Alcázar, P. Molas, C. Bo and S. Castillón, J. Org. Chem., 2003, 68, 686.

12 (a) B. Yang, W. Yang, S. Ramadan and X. Huang, Eur. J. Org. Chem., 2018, 1075; (b) W. Yang, B. Yang, S. Ramadan and X. Huang, Beilstein J. Org. Chem., 2017, 13, 2094; (c) M. A. Fascione, R. Brabham and W. B. Turnbull, Chem.Eur. J., 2016, 22, 3916; (d) M. C. Aversa, A. Barattucci and P. Bonaccorsi, Tetrahedron, 2008, 64, 7659.

13 D. Kahne, S. Walker, Y. Cheng and D. Van Engen, J. Am. Chem. Soc., 1989, 111, 6881.

14 S. P. Vincent, M. D. Burkart, C.-Y. Tsai, Z. Zhang and C.-H. Wong, J. Org. Chem., 1999, 64, 5264.

15 R. Curci, R. A. DiPrete, J. O. Edwards and G. Modena, J. Org. Chem., 1970, 35, 740.

16 (a) T. Taniguchi, M. Asahata, A. Nasu, Y. Shichibu, K. Konishi and K. Monde, Chirality, 2016, 28, 534; (b) J. F. Moya-López, E. Elhalem, R. Recio, E. Álvarez, I. Fernández and N. Khiar, Org. Biomol. Chem., 2015, 13, 1904.

17 (a) N. Aiguabella, M. C. Holland and R. Gilmour, Org. Biomol. Chem., 2016, 14, 5534; (b) N. Santschi and R. Gilmour, Eur. J. Org. Chem., 2015, 6983; (c) E. Durantie, C. Bucher and R. Gilmour, Chem.-Eur. J., 2012, 18, 8208; (d) C. Bucher and R. Gilmour, Angew. Chem., Int. Ed., 2010, 49, 8724; (e) J. A. C. Romero, S. A. Tabacco and K. A. Woerpel, J. Am. Chem. Soc., 2000, 122, 168; (f) R. J. Woods, C. W. Andrews and J. P. Bowen, J. Am. Chem. Soc., 1992, 114, 850; $(g)$ R. J. Woods, C. W. Andrews and J. P. Bowen, J. Am. Chem. Soc., 1992, 114, 859. 